\title{
PENGARUH PERSONAL KNOWLEDGE, JOB PROCEDURE DAN TECHNOLOGY TERHADAP KINERJA PEGAWAI ORGANISASI PUBLIK
}

\author{
Azwar Iskandar \\ Balai Diklat Keuangan Makassar \\ Email: azwar.iskandar@gmail.com \\ Achmat Subekan \\ Balai Diklat Keuangan Makassar \\ Email: achmatsubekan@gmail.com
}

\begin{abstract}
ABTRAK
Penelitian ini bertujuan untuk menganalisis pengaruh personal knowledge, job procedure dan technology dalam konteks knowledge management terhadap Performance (Kinerja Pegawai) di lingkungan organisasi publik, secara khusus pada lingkungan Badan Pendidikan dan Pelatihan (BPPK) Kementerian Keuangan. Populasi dalam penelitian ini adalah seluruh pegawai di lingkungan BPPK. Sampel penelitian diperoleh dengan teknik simple random sampling. Dengan menggunakan teknis analisis jalur (path analysis), penelitian menemukan bahwa (1) personal knowledge tidak terbukti secara signifikan memengaruhi performance (kinerja pegawai), job procedure terbukti secara signifikan memengaruhi performance (kinerja) pegawai, dan technology terbukti secara signifikan memengaruhi performance (kinerja) pegawai; (2) personal knowledge terbukti secara signifikan memengaruhi pemahaman pegawai akan job procedure organisasi; dan (3) personal knowledge dalam pengaruh tidak langsung terbukti secara signifikan memengaruhi performance (kinerja) pegawai yang dimediasi oleh job procedure.
\end{abstract}

Kata kunci: Pengetahuan, teknologi, kinerja 


\section{PENDAHULUAN}

Agenda reformasi birokrasi di lingkungan pemerintah, khususnya pada Kementerian Keuangan, bertumpu pada penataan dan penajaman fungsi organisasi, penyempurnaan proses bisnis (business process), dan peningkatan kualitas Sumber Daya Manusia (SDM). Dalam rangka pencapaian dan pengelolaan kinerja organisasi, Badan Pendidikan dan Pelatihan Keuangan (BPPK) sebagai salah satu unit kerja di lingkungan Kementerian Keuangan saat ini gencar menerapkan konsep knowledge management sebagai bagian dari bentuk implementasi Corporate University yang dicita-citakan. Upaya ini merupakan salah satu strategi BPPK untuk mewujudkan pendidikan dan pelatihan yang fleksibel dalam memenuhi kebutuhan unit pengguna yaitu dengan pengembangan manajemen pengetahuan (knowledge management) untuk kebutuhan pendidikan dan pelatihan yang diarahkan untuk menjadi bagian utama dalam pengembangan sistem manajemen pengetahuan Kementerian Keuangan.

Takeuchi (1998), Honeycutt (2005), Debowski (2006) dan Nawawi (2012) menyebutkan bahwa Knowledge (pengetahuan) terdiri dari dua jenis, yaitu pengetahuan yang terbatinkan atau pemikiran pengetahuan (tacit knowledge) dan pengetahuan sudah terekam dan termodifikasi dalam dokumen (explicit knowledge). Tacit knowledge merupakan knowledge yang diam dalam benak manusia dalam bentuk instuisi, judgment, skill, nilai (value), dan belief yang sangat sulit diformulasikan dan dibagikan kepada orang lain. Pada dasarnya tacit knowledge bersifat personal, dikembangkan melalui pengalaman yang sulit untuk diformulasikan dan dikomunikasikan (Carrillo et al.,2004). Tacit knowledge tidak dinyatakan dalam bentuk tulisan, melainkan sesuatu yang terdapat dalam benak orang-orang yang bekerja di dalam suatu organisasi. Secara garis besar, personal knowledge berarti gabungan dari pengalaman, nilai-nilai, informasi kontekstual, dan wawasan luas yang menyediakan sebuah kerangka pengetahuan untuk mengevaluasi dan menggabungkan pengalaman-pengalaman dan informasi yang baru.

Explicit knowledge adalah knowledge yang dapat atau sudah dikodifikasikan dalam bentuk dokumen atau bentuk wujud lainnya sehingga dapat mudah ditransfer dan didistribusikan dengan menggunakan berbagai media. Penerapan explicit knowledge ini lebih mudah karena pengetahuan yang diperoleh dalam bentuk tulisan atau pernyataan yang didokumentasikan, sehingga setiap karyawan dapat mempelajarinya secara 
independen. Penerapan explicit knowledge ini dapat berupa job procedure dan technology. Technology merupakan salah satu elemen pokok yang terdapat pada knowledge management, dikenal sebagai media yang mempermudah penyebaran explicit knowledge.

Intranet merupakan salah satu bentuk teknologi yang diterapkan di Kementerian Keuangan secara umum dan BPPK secara khusus. Intranet atau (internal internet) menawarkan kesempatan untuk menggunakan telekomunikasi yang dikembangkan dari internet management yang utama untuk menjalankan dan mendukung forum diskusi dan praktik. Intranet BPPK adalahaplikasi komunikasi berbasis web (online) yang hanya diperuntukkan bagi kalangan SDM di lingkungan BPPK. Di dalam situs tersebut terdapatmenu-menu (ikon) aplikasi perkantoran dan keuangan serta bisnis proses yang dipergunakan dan diperuntukkan bagi keperluan di lingkungan BPPK. Di samping itu, intranet BPPK juga berfungsi sebagai ajang pertukaran informasi dan knowledge antarindividu, baik yang dilakukan secara langsung maupun tidak langsung, yakni melalui aplikasi forum chatting atau social ataupun komunikasi tidak langsung lainnya seperti aplikasi Forum Diskusi yang telah dibagi berdasarkan bidang-bidang tertentu. Pada beberapa tahun terakhir, perkembangan intranet BPPK semakin pesat dengan adanya fitur streaming-streaming video hasil liputan atau event tertentu yang berkaitan dengan BPPK dan Kementerian Keuangan.

Prinsip-prinsip umum knowledge management yang telah diimplementasikan sejak beberapa tahun terakhir di lingkungan BPPK diantaranya berupa budaya knowledge sharing yang telah dibangun dan dilaksanakan di lingkungan Kementerian Keuangan secara umum dan BPPK secara khusus melalui budaya One Day One Information (Satu Informasi Setiap Hari). Berdasarkan Keputusan Menteri Keuangan Republik Indonesia Nomor 127/KMK.01/2013, budaya ini dimaksudkan untuk mendorong seluruh Pegawai Negeri Sipil dan Calon Pegawai Negeri Sipil Kementerian Keuangan mencari informasi yang positif dan membaginya (sharing) kepada Pegawai Kementerian Keuangan lainnya sehingga menjadi pengetahuan bersama. Selain itu, keberadaan intranet BPPK (COMET) sejak beberapa tahun lalu yang dilengkapi dengan banyaknya fitur knowledge sharing juga menjadi alasan yang kuat bahwa knowledge management telah lama ada dan diterapkan di lingkungan BPPK. 
Berdasarkan uraian di atas, kajian empiris terkait penerapan knowledge management serta implikasinya terhadap pencapaian kinerja pegawai dan organisasi di lingkungan Kementerian Keuangan khususnya pada BPPK menjadi penting untuk dilakukan. Hal ini didasarkan pada pertimbangan bahwa penerapan knowledge management tersebut merupakan sesuatu yang relatif baru dalam organisasi publik di Indonesia. Sebuah organisasi perlu melihat sejauh mana sebuah sistem atau manajemen baru dapat diterima dan berhasil berjalan dengan baik sesuai dengan yang diharapkan, sehingga perlu untuk menjawab permasalahan yang muncul tentang bagaimana pengaruh penerapan knowledge management tersebut terhadap kinerja pegawai.

Oleh karena itu, penelitian ini dilakukan dengan tujuan untuk : (1) menganalisis pengaruh personal knowledge, job procedure, dan technology terhadap performance (kinerja pegawai); (2) menganalisis pengaruh personal knowledge terhadap pemahaman pegawai akan job procedure; dan (3) menganalisis pengaruh tidak langsung personal knowledge terhadap performance (kinerja pegawai) yang dimediasi oleh pemahaman pegawai akan job procedure. Indikator knowledge management yang digunakan dalam penelitian ini mengacu pada indikator yang dibangun oleh Nonaka dan Takeuchi (1995), Honeycutt (2005) dan Debowski (2006). Inidikator-indikator ini dipilih sebagai model knowledge management yang dikaji karena indikator-indikator tersebut diyakini dapat mewakili kondisi knowledge management system yang saat ini diterapkan di lingkungan BPPK. Selain itu, indikator-indikator tersebut secara empiris telah diterapkan dalam penelitian-penelitian terdahulu dan menghasilkan implikasi atau rekomendasi hasil riset yang baik.

Penelitian ini berbeda dari penelitian-penelitian sebelumnya karena penelitian ini menguji pengaruh indikator penerapan knowledge management terhadap kinerja pada organisasi publik (pemerintah) di Indonesia, dimana hal tersebut belum ditemukan pada penelitian-penelitian sebelumnya. Selain itu, penelitian ini menggunakan data konversi ordinal ke interval, dimana konversi data tersebut tidak dilakukan pada penelitianpenelitian sebelumnya. Secara akademis, penelitian ini diharapkan dapat memberikan bukti empiris tentang dampak penerapan knowledge management di lingkungan BPPK secara khusus dan organisasi publik secara umum, terhadap pencapaian kinerja pegawai berdasarkan sudut pandang pegawai. Penelitian ini juga diharapkan dapat menambah referensi penelitian berikutnya dalam bidang manajemen sumber daya aparatur, 
khususnya dalam kajian terkait pengelolaan pengetahuan di organisasi sektor publik. Secara praktis, hasil penelitian ini diharapkan dapat dijadikan bahan pertimbangan bagi pemegang kebijakan yang terkait dengan kebijakan impelementasi knowledge management organisasi, khususnya pada sektor publik.

\section{TELAAH PUSTAKA}

\section{Knowledge Management}

Tiwana (2000) mendefinisikan knowledge management secara luas dalam arti manajemen pengetahuan sebagai "management of organizational knowledge for creating business value and generating a competitive advantage." Knowledge management memberikan kemampuan untuk menciptakan, mengomunikasikan, dan menerapkan pengetahuan yang diperlukan guna pencapaian semua jenis tujuan bisnis. Tiwana juga menjelaskan "knowledge management is the ability to create and retain greater value from core business competencies". Knowledge management menyelesaikan masalah bisnis partikular yang mencakup penciptaan dan penyebaran barang atau jasa inovatif, mengelola dan memperbaiki hubungan dengan para pelanggan, mitra dan pemasok, serta mengadministrasikan dan meningkatkan praktik dan proses kerja.

Menurut Laudon dan Laudon (2008), knowledge management berfungsi meningkatkan kemampuan organisasi untuk belajar dari lingkungannya dan menggabungkan pengetahuan ke dalam proses bisnis. Knowledge management adalah serangkaian proses yang dikembangkan dalam suatu organisasi untuk menciptakan, mengumpulkan, memelihara, dan mendiseminasikan pengetahuan organisasi tersebut.

Nonaka dan Takeuchi (1995), Honeycutt (2005), Debowski (2006) dan Nawawi (2012) menyebutkan bahwa Knowledge (pengetahuan) terdiri dari dua jenis, yaitu pengetahuan yang terbatinkan atau pemikiran pengetahuan (tacit knowledge) dan pengetahuan sudah terekam dan termodifikasi dalam dokumen (explicit knowledge). Tacit knowledge merupakan knowledge yang diam dalam benak manusia dalam bentuk instuisi, judgment, skill, nilai (value), dan belief yang sangat sulit diformulasikan dan dibagikan kepada orang lain. Sedangkan explicit knowledge adalah knowledge yang dapat atau sudah dikodifikasikan dalam bentuk dokumen atau bentuk wujud lainnya sehingga dapat mudah ditransfer dan didistribusikan dengan menggunakan berbagai media. 
Pada dasarnya tacit knowledge bersifat personal, dikembangkan melalui pengalaman yang sulit untuk diformulasikan dan dikomunikasikan (Carrillo et al., 2004). Tacit knowledge tidak dinyatakan dalam bentuk tulisan, melainkan sesuatu yang terdapat dalam benak orang-orang yang bekerja di dalam suatu organisasi. Menurut Polanyi (1966), tacit knowledge secara umum dijabarkan sebagai: pemahaman dan aplikasi pikiran bawah sadar, susah untuk diucapkan, berkembang dari kejadian langsung dan pengalaman, dan berbagi pengetahuan melalui percakapan (story-telling). Selanjutnya menurut Bahm (1995) penelitian pada sifat dasar pengetahuan seketika mempertemukan perbedaan antara knower dan known, atau seringkali diartikan dalam istilah subject dan object, atau ingredient subjective dan objective dalam pengalaman. Pengalaman yang diperoleh tiap karyawan tentunya berbeda-beda berdasarkan situasi dan kondisi yang tidak dapat diprediksi. Definisi experience yang diambil dari kamus bahasa Inggris adalah "the process of gaining knowledge or skill over a period of time through seeing and doing things rather than through studying" yang artinya proses memperoleh pengetahuan atau kemampuan selama periode tertentu dengan melihat dan melakukan hal-hal disamping belajar secara biasa. Secara garis besar, personal knowledge berarti gabungan dari pengalaman, nilai-nilai, informasi kontekstual, dan wawasan luas yang menyediakan sebuah kerangka pengetahuan untuk mengevaluasi dan menggabungkan pengalaman-pengalaman dan informasi yang baru.

Adapun explicit knowledge bersifat formal dan sistematis yang mudah untuk dikomunikasikan dan dibagi (Carrillo et al., 2004). Menurut pernyataan Polanyi (1966) pada saat tacit knowledge dapat dikontrol dalam benak seseorang, explicit knowledge justru harus bergantung pada pemahaman dan aplikasi secara tacit, maka dari itu semua pengetahuan berakar dari tacit knowledge. Secara umum explicit knowledge dapat dijabarkan sebagai pengetahuan yang dapat diucapkan secara tepat dan resmi, mudah disusun, didokumentasikan, dipindahkan, dibagi, dan dikomunikasikan. Penerapan explicit knowledge ini lebih mudah karena pengetahuan yang diperoleh dalam bentuk tulisan atau pernyataan yang didokumentasikan, sehingga setiap karyawan dapat mempelajarinya secara independen. Penerapan explicit knowledge ini dapat berupa job procedure dan technology.

Interaksi antara tacit dan explicit knowledge ini disebut sebagai proses konversi knowledge (process of knowledge conversion). Proses konversi dapat berasal dari 
knowledge yang bersifat tacit diubah menjadi knowledge yang bersifat explicit. Apabila knowledge telah berubah menjadi tacit, maka knowledge siap digunakan untuk menghasilkan produk baru dan melakukan pelayanan yang lebih baik. Sementara itu, apabila knowledge telah diubah menjadi explicit, maka knowledge siap untuk ditransfer kepada seluruh karyawan dalam perusahaan atau diubah ke dalam expertsystem.

Manajemen pengetahuan saat ini tidak hanya dikenal dalam perusahaan swasta (private sector), tetapi juga sudah dikenal pada organisasi pemerintahan (public sector). Penerapan knowledge management di organisasi pemerintahan hampir sama dengan organisasi swasta. Perbedaannya, organisasi swasta bertujuan pada profit, sedangkan organisasi pemerintahan bertujuan pada peningkatan kinerja pegawai, organisasi, dan layanan publik. Sejumlah literatur menunjukkan bahwa organisasi pemerintahan telah menginisiasi penerapan manajemen pengetahuan. Penerapan knowledge management pada organisasi pemerintahan ditujukan untuk mempermudah proses penciptaan, pengumpulan, penyimpanan, berbagi-tukar pengetahuan (knowledge sharing), menutup kesenjangan pengetahuan antara satu karyawan dengan karyawan lainnya, dan meningkatkan kemampuan organisasi dalam mengelola aset intelektual, pengetahuan dan pengalaman yang ada.

\section{Job Procedure dan Technology}

Job procedure atau prosedur kerja adalah tanggung jawab atau tugas yang bersifat formal atau perintah resmi atau cara melakukan hal-hal tertentu. Salah satu bentuk konkret dari explicit knowledge adalah Standard Operation Procedure yaitu prosedur pelaksanaan dasar yang dibuat untuk mempertahankan kualitas dan hasil kerja. Dengan menggunakan Standard Operation Procedure maka tugas-tugas akan semakin mudah dikerjakan. Standard Operation Procedure sendiri dalam pelaksanaannya sangat fleksibel dimana karyawan dapat memberikan masukan berdasarkan pengetahuan yang diperoleh. Lebih lanjut menurut Sulastiyono (2001), agar suatu jenis pekerjaan dapat menghasilkan produk yang standar dari waktu ke waktu, maka cara-cara mengerjakan untuk menghasilkan produk tersebut harus dilakukan dengan cara-cara yang standar pula. Keuntungan yang dapat diperoleh dengan adanya dan digunakannya Standard Operation Procedure (SOP) diantaranya adalah terwujudnya SOP tersebut sebagai alat atau saluran komunikasi bagi manajemen dengan para staf dan para pelaksananya. Melalui Standard Operation Procedure, seluruh staf dan karyawan akan mengetahui 
secara jelas, berusaha untuk memahami tentang tujuan dan sasaran, serta kebijakan dan prosedur kerja perusahaan. Standard Operation Procedure juga dapat digunakan sebagai alat atau acuan untuk melaksanakan pelatihan baik bagi para staf/karyawan lama maupun staf/karyawan baru. Standard Operation Procedure dapat mengurangi waktu yang terbuang sehingga dapat meningkatkan produktivitas kerja baik bagi manajemen maupun bagi para staf/karyawan. Dengan dibantu oleh pengawasan yang dilaksanakan dalam proses pekerjaan, maka Standard Operation Procedure dapat dilaksanakan secara lebih konsisten, dan menjamin terciptanya produk yang standar, sekalipun dikerjakan oleh orang-orang yang berbeda dan pada waktu pelaksanaan yang tidak bersamaan.

Technology merupakan salah satu elemen pokok yang terdapat pada knowledge management, dikenal sebagai media yang mempermudah penyebaran explicit knowledge. Berdasarkan pernyataan Gillingham dan Roberts (2006), awal mulanya knowledge management digerakkan oleh teknologi, khususnya explicit knowledge yang lebih mudah disusun. Menurut Marwick (2001) teknologi bukanlah hal baru dalam knowledge management. Pengalaman yang telah dibentuk oleh para ahli sebelumnya menjadi bahan pertimbangan terbentuknya teknologi itu sendiri. Seiring dengan berjalannya waktu, teknologi yang mendukung knowledge management akan selalu berkembang dalam bentuk sistem-sistem yang mempermudah proses penyebaran knowledge. Salah satu teknologi paling mutakhir yang saat ini digunakan oleh banyak perusahaan dan organisasi untuk proses penyebaran knowledge adalah intranet. Hal ini didasarkan pada kebutuhan untuk mengakses knowledge dan melakukan kolaborasi, komunikasi, serta berbagi knowledge secara online.

Intranet merupakan salah satu bentuk teknologi yang diterapkan di Kementerian Keuangan secara umum dan BPPK secara khusus. Intranet atau (internal internet) menawarkan kesempatan untuk menggunakan telekomunikasi yang dikembangkan dari internet. Menurut Merali (1999) dalam Herusantoso dan Lasahido (2011), peralatan seperti intranet dan internet dianggap sebagai sistem knowledge management yang utama untuk menjalankan dan mendukung forum diskusi dan praktik. Intranet BPPK mulai beroperasi pada tahun 2009 diprakarsai oleh Bidang Teknologi Informasi dan Komunikasi (TIK) Sekretariat Badan BPPK. Intranet BPPK adalah aplikasi komunikasi berbasis web (online) yang hanya diperuntukkan bagi kalangan SDM di lingkungan 
BPPK dengan login menggunakan password masing-masing individu melalui jaringan Pusat Informasi dan Teknologi (Pusintek). Di dalam situs tersebut terdapat menu-menu (ikon) aplikasi perkantoran dan keuangan serta bisnis proses yang dipergunakan dan diperuntukkan bagi keperluan di lingkungan BPPK. Di samping itu, intranet BPPK juga berfungsi sebagai ajang pertukaran informasi dan knowledge antarindividu, baik yang dilakukan secara langsung maupun tidak langsung, yakni melalui aplikasi forum chatting atau social ataupun komunikasi tidak langsung lainnya seperti aplikasi Forum Diskusi yang telah dibagi berdasarkan bidang-bidang tertentu. Aplikasi komunikasi ini sangat diminati SDM BPPK. Hal ini terlihat dengan banyaknya partisipan dalam forum chatting dan forum diskusi. Selain itu, berita-berita seputar BPPK, baik berupa kegiatan maupun produk-produk hukum dan persuratan di lingkungan BPPK lebih cepat diupload dan di-download oleh pihak yang berkepentingan. Pada beberapa tahun terakhir, perkembangan intranet BPPK semakin pesat dengan adanya fitur streamingstreaming video hasil liputan atau event tertentu yang berkaitan dengan BPPK dan Kementerian Keuangan.

\section{Kinerja}

Performance (kinerja) merupakan hasil kerja atau karya yang dihasilkan oleh masing-masing karyawan untuk membantu badan usaha atau organisasi dalam mencapai dan mewujudkan tujuan badan usaha atau organisasi. Pada dasarnya kinerja dari seseorang merupakan hal yang bersifat individu karena masing-masing karyawan memiliki tingkat kemampuan yang berbeda. Kinerja seseorang bergantung pada kombinasi dari kemampuan, usaha, dan kesempatan yang diperoleh (Dale, 1992).

Secara khusus, pengelolaan kinerja di Kementerian Keuangan diatur dengan Keputusan Menteri Keuangan Nomor 467/KMK.01/2014 tentang Pengelolaan Kinerja di Lingkungan Kementerian Keuangan. Pengelolaan kinerja di Kementerian Keuangan termasuk di lingkungan BPPK mencakup pengelolaan kinerja pegawai dan pengelolaan kinerja organisasi bagi unit eselon I dan/atau pegawai di lingkungan Kementerian Keuangan. Pengelolaan kinerja di Kementerian Keuangan dikoordinasikan oleh Kepala Pusat Analisis dan Harmonisasi Kebijakan selaku Manajer Kinerja Organisasi Pusat untuk pengelolaan kinerja organisasi; dan Kepala Biro Sumber Daya Manusia Setjen Kementerian Keuangan selaku Manajer Kinerja Pegawai Pusat untuk pengelolaan kinerja pegawai. Pengelolaan kinerja di lingkungan Kementerian Keuangan 
didokumentasikan dalam sebuah aplikasi berbasis online dengan alamat: http://eperformance.kemenkeu.go.id.

Dari penjelasan ini, penelitian ini hendak menguji hipotesis yang menyatakan bahwa:

$\mathrm{H}_{1}$ : personal knowledge secara signifikan memengaruhi performance (kinerja pegawai).

$\mathrm{H}_{2}$ : job procedure organisasi secara signifikan memengaruhi performance (kinerja pegawai).

$\mathrm{H}_{3}$ : technology secara signifikan memengaruhi performance (kinerja pegawai).

$\mathrm{H}_{4} \quad$ : personal knowledge secara signifikan memengaruhi job procedure organisasi

$\mathrm{H}_{5}$ : personal knowledge secara signifikan memengaruhi performance (kinerja pegawai) yang dimediasi oleh variabel job procedure organisasi.

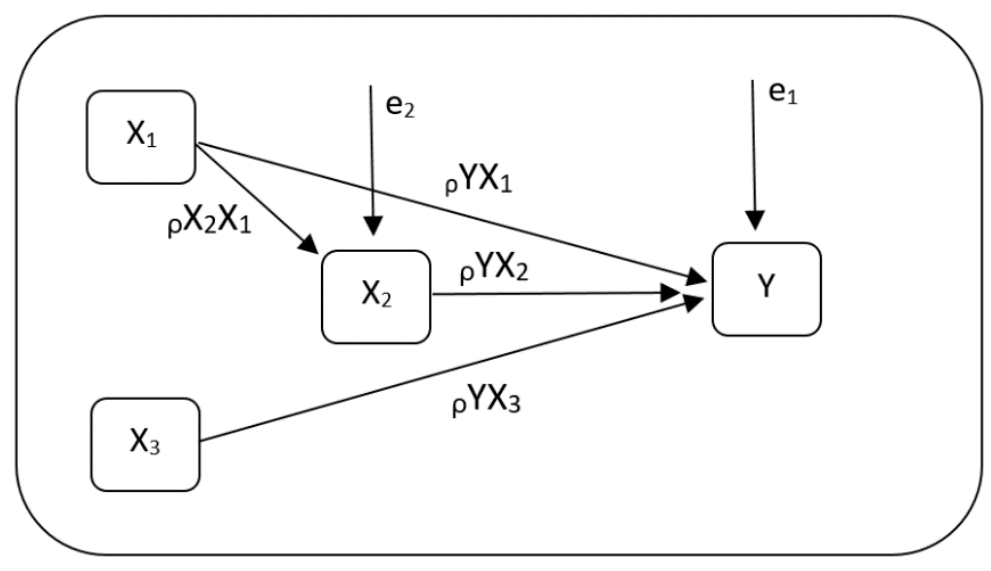

Gambar 1. Kerangka Pemikiran

Kerangka pemikiran dalam penelitian ini disusun berdasarkan tinjauan pustaka, penelitian terdahulu, dan hipotesis yang menjelaskan gambaran secara umum dampak knowledge management terhadap kinerja pegawai, sebagaimana digambarkan pada Gambar 1.

\section{METODE PENELITIAN}

Penelitian ini merupakan penelitian studi kasus, yakni penelitian tentang status subjek penelitian yang berkenaan dengan suatu fase spesifik atau khas dari keseluruhan personalitas (Nazir, 2003). Sementara, dilihat dari permasalahan yang diteliti, penelitian ini merupakan penelitian kausalitas yang bertujuan untuk menganalisis hubungan atau pengaruh (sebab-akibat) dari dua atau lebih fenomena melalui pengujian hipotesis (Sekaran, 2006). 

http://doi.org/10.21009/JRMSI

Sumber data yang digunakan dalam penelitian berasal dari data primer dan data sekunder. Data primer diperoleh langsung dari responden melalui kuesioner yang dibagikan. Sedangkan data sekunder diperoleh dan disajikan oleh pihak-pihak lainnya seperti dokumen Standard Operation Procedure (SOP) di lingkungan BPPK, dokumen dan peraturan pengelolaan kinerja pegawai di lingkungan BPPK dan lainnya. Populasi dalam penelitian ini adalah seluruh pegawai (fungsional dan struktural) BPPK yang berasal dari seluruh satuan kerja di lingkungan BPPK baik dari Pusdiklat maupun Balai Diklat.Jumlah pegawai yang menjadi populasi penelitian adalah sebanyak 1.316 pegawai per 31 Januari 2017 (http://www.bppk.depkeu.go.id/profil/sdm/pegawai-bppk). Mengingat bahwa pegawai di lingkungan BPPK relatif homogen dalam penerapan knowledge management maka teknik pengambilan sampel yang digunakan dalam penelitian ini adalah simple random sampling. Untuk menentukan jumlah sampel, penelitian ini menggunakan rumus Slovin sebagai berikut (Ariola, 2006): $\mathrm{n}=\mathrm{N} /[1+(\mathrm{N}$. $\left.\alpha^{2}\right)$ ], dimana $\mathrm{n}=$ jumlah sampel penelitian, $\mathrm{N}=$ Jumlah populasi penelitian, dan $\alpha=$ error level (tingkat kesalahan). Dengan menggunakan rumus Slovin di atas dan tingkat kesalahan (errorlevel) sebesar 5\% (tingkat signifikansi) maka jumlah sampel penelitian ini ditetapkan sebanyak 307 orang.

Penelitian ini menggunakan empat variabel sesuai dengan model kerangka pemikiran yang dibangun berdasarkan indikator knowledge management oleh Nonaka dan Takeuchi (1995), Honeycutt (2005) dan Debowski (2006) yaitu terdiri dari variabel eksogen dan variabel endogen. Varibel eksogen adalah variabel independen (bebas) yang memengaruhi variabel dependen (terikat) yang ditunjukkan dengan adanya anak panah yang berasal dari variabel tersebut menuju variabel endogen dalam model. Sedangkan variabel endogen adalah variabel dependen (terikat) yang dipengaruhi oleh variabel independen (bebas) yang ditunjukkan dengan adanya anak panah yang menuju variabel tersebut dalam model. Variabel eksogen penelitian ini terdiri atas: personal knowledge, job procedure dan technology. Sedangkan variabel endogen penelitian ini terdiri atas job procedure dan performance (kinerja pegawai). Seluruh variabel diukur dengan data Skala Likert (ordinal) dengan skala 1 - 5 yang terdiri dari : Sangat Setuju (5), Setuju (4), Kurang Setuju (3), Tidak Setuju (2), dan Sangat Tidak Setuju (1).

Tabel 1. Indikator Pengukuran Variabel Penelitian

$\begin{array}{llll}\text { Varaiabel } & \text { No. } & \text { Indikator } & \text { Referensi }\end{array}$




\begin{tabular}{|c|c|c|c|}
\hline Personal & 1 & Pengalaman kerja dan profesionalitas. & Kosasih dan Budiani \\
\hline \multirow[t]{10}{*}{ Knowledge $\left(\mathrm{X}_{1}\right)$} & 2 & Pengalaman dari diri sendiri dan orang lain. & $(2007)$ \\
\hline & 3 & Pengalaman baru. & \\
\hline & 4 & Pengalaman yang memperkaya pengetahuan. & \\
\hline & 5 & Pengalaman dari bagian atau unit lain. & \\
\hline & 6 & Mengomunikasikan pengalaman kerja. & \\
\hline & 7 & $\begin{array}{l}\text { Forum "sharing best practices" atau "sharing } \\
\text { knowledge". }\end{array}$ & \\
\hline & 8 & $\begin{array}{l}\text { Manfaat "sharing best practices" atau "sharing } \\
\text { knowledge". }\end{array}$ & \\
\hline & 9 & Permasalahan dalam pekerjaan. & \\
\hline & 1 & Standar produk (output). & Bernardin dan Russel \\
\hline & 2 & Arah dan koordinasi pekerjaan. & $(1993)$ \\
\hline \multirow{7}{*}{$\begin{array}{l}\text { Job Procedure } \\
\qquad\left(\mathrm{X}_{2}\right)\end{array}$} & 3 & Sasaran dan tujuan organisasi. & \\
\hline & 4 & Tanggung jawab pekerjaan. & \\
\hline & 5 & Produktivitas kerja dan efisiensi waktu. & \\
\hline & 6 & Pemahamanpekerjaan. & \\
\hline & 7 & Standar SOP di setiap unit/seksi. & \\
\hline & 1 & Produktifitas. & Herusantoso dan Lasahido \\
\hline & 2 & Manfaat. & $(2012)$ \\
\hline \multirow{7}{*}{$\begin{array}{l}\text { Technology } \\
\qquad\left(\mathrm{X}_{3}\right)\end{array}$} & 3 & Penyelesaiaan pekerjaan lebih cepat. & \\
\hline & 4 & Kualitas output pekerjaan. & \\
\hline & 5 & Peningkatan efektivitas pekerjaan. & \\
\hline & 6 & Sarana penyebaran informasi. & \\
\hline & 1 & Mendukung capaian IKU. & Keputusan Menteri \\
\hline & 2 & Mendukung capaian Nilai Perilaku (NP). & Keuangan Nomor \\
\hline & 3 & Mendukung capaian Nilai DP3. & 467/KMK.01/2014 tentang \\
\hline \multirow{4}{*}{$\begin{array}{l}\text { Performance } \\
\text { (Y) }\end{array}$} & 4 & $\begin{array}{l}\text { Mendukung kualitas (quality) hasil (output) } \\
\text { pekerjaan. }\end{array}$ & $\begin{array}{l}\text { Pengelolaan Kinerja di } \\
\text { Lingkungan Kementerian }\end{array}$ \\
\hline & 5 & $\begin{array}{l}\text { Mendukung kuantitas (quantity) hasil (output) } \\
\text { pekerjaan. }\end{array}$ & Keuangan \\
\hline & 6 & Penyelesaian pekerjaan (timelines). & \\
\hline & 7 & Berbagi dan bekerja sama (interpersonal impact). & \\
\hline
\end{tabular}

Sumber: Data diolah oleh peneliti

Penelitian ini menggunakan teknik analisis statistika inferensial berupa analisis jalur (path analysis) dengan bantuan program komputer IBM Statistics SPSS 22. Model analisis jalur sebagaimana diungkapkan oleh Bohrnstedt, dalam Kusnendi (2008), digunakan untuk menganalisis pola hubungan antarvariabel dengan tujuan untuk mengetahui pengaruh langsung maupun tidak langsung seperangkat variabel penyebab (variabel eksogen) terhadap satu set variabel akibat (variabel endogen).

Dalam penggunaan analisis jalur (path analysis), menurut Solimun dalam Somad (2013), ada beberapa asumsi yang harus dipenuhi, antara lain: a) Observed variable diukur tanpa kesalahan (instrumen pengukuran harus valid dan reliabel); b) Hubungan antarvariabel dalam model analisis jalur adalah linear; c) Hanya model rekursif (sistem aliran kausal ke satu arah) yang dapat dipertimbangkan sedangkan pada model yang mengandung kausal resiprokal (sistem aliran kausal timbal balik) tidak 
dipertimbangkan; d) Variabel endogen dan eksogen minimal dalam ukuran skalaukur interval; e) Model yang dianalisis dispesifikasikan (diidentifikasi) dengan benar berdasarkan teori-teori dan konsep yang relevan. Oleh karena itu, instrumen dan data penelitian terlebih dahulu akan melalui Uji Realibilitas, Uji Validitas Data, Uji Linieritas dan Uji Normalitas.Mengingat data variabel penelitian berskala ordinal, maka terhadap data tersebut, sebelum dianalisis dalam model analisis jalur, terlebih dahulu ditransformasikan ke dalam skala interval dengan menggunakan Methods of Successive Intervals (MSI) seperti yang diungkapkan oleh Hays dalam Somad (2013).Untuk memudahkan transformasi data, peneliti menggunakan bantuan program Microsoft Excel 2013. Berdasarkan kerangka pikir dan teknik peneitian, maka model struktural penelitian dirumuskan sebagai berikut :

(1) $\mathrm{Y}={ }_{\rho} \mathrm{X}_{1} \mathrm{Y}+{ }_{\rho} \mathrm{X}_{2} \mathrm{Y}+{ }_{\rho} \mathrm{X}_{3} \mathrm{Y}+\mathrm{e}_{1}$

(2) $X_{2}={ }_{\rho} X_{1} X_{2}+e_{2}$,

dimana $\mathrm{X}_{1}=$ Personal Knowledge, $\mathrm{X}_{2}=$ Job Procedure, $\mathrm{X}_{3}=$ Technology, $\mathrm{Y}=$ Performance, dan a,b, c, dan $\mathrm{d}=$ koefisien regresi path analysis dan $\mathrm{e}=$ nilai error.

\section{HASIL DAN PEMBAHASAN}

\section{Uji Validitas dan Realibilitas}

Menurut Ghozali (2006) uji validitas digunakan untuk mengukur sah atau valid tidaknya suatu kuesioner. Suatu kuesioner dikatakan valid jika pertanyaan pada kuesioner mampu untuk mengungkapkan sesuatu yang akan diukur oleh kuesioner tersebut. Uji signifikansi dilakukan dengan cara membandingkan nilai $r$ hitung dengan $r$ tabel untuk degree of freedom $(\mathrm{df})=\mathrm{n}-2$, dalam hal ini $\mathrm{n}$ adalah jumlah sampel. Untuk menguji apakah masing-masing indikator valid atau tidak, dapat dilihat dalam tampilan output Cronbach Alpha pada kolom Correlated Item-Total Correlation(r). Jika r hitung lebih besar dari $\mathrm{r}$ tabel dan nilai positif maka butir atau pertanyaan atau indikator tersebut dinyatakan valid (Ghozali, 2006). Berdasarkan Hasil Uji Validitas terhadap data penelitian, dengan membandingkan masing-masing nilai $\mathrm{r}$ hitung (Correlation Item-Total Correlation) pada setiap item pertanyaan dengan $\mathrm{r}$ tabel untuk degree of freedom $(\mathrm{df})=\mathrm{n}-2$, di mana $\mathrm{r}$ tabel $=0.3115$, ditemukan bahwa semua nilai $\mathrm{r}$ hitung masing-masing pertanyaan yang digunakan sebagai instrumen untuk mengukur vaiabel penelitian adalah lebih besar dari nilai $r$ tabel (Lihat Tabel 2). Sehingga dapat 
dinyatakan bahwa instrumen penelitian untuk mengukur seluruh variabel dalam penelitian ini adalah valid.

Tabel 2. Hasil Uji Validitas

\begin{tabular}{|c|c|c|c|}
\hline Variabel & Item Pertanyaan & Corrected Item-Total Correlation & Keterangan \\
\hline Personal & 1 & 0.458 & Valid \\
\hline \multirow[t]{8}{*}{ Knowledge } & 2 & 0.642 & Valid \\
\hline & 3 & 0.660 & Valid \\
\hline & 4 & 0.613 & Valid \\
\hline & 5 & 0.451 & Valid \\
\hline & 6 & 0.664 & Valid \\
\hline & 7 & 0.699 & Valid \\
\hline & 8 & 0.747 & Valid \\
\hline & 9 & 0.567 & Valid \\
\hline \multirow[t]{7}{*}{ Job Procedure } & 1 & 0.822 & Valid \\
\hline & 2 & 0.832 & Valid \\
\hline & 3 & 0.711 & Valid \\
\hline & 4 & 0.813 & Valid \\
\hline & 5 & 0.770 & Valid \\
\hline & 6 & 0.659 & Valid \\
\hline & 7 & 0.633 & Valid \\
\hline \multirow[t]{6}{*}{ Technology } & 1 & 0.889 & Valid \\
\hline & 2 & 0.823 & Valid \\
\hline & 3 & 0.908 & Valid \\
\hline & 4 & 0.924 & Valid \\
\hline & 5 & 0.907 & Valid \\
\hline & 6 & 0.801 & Valid \\
\hline \multirow[t]{7}{*}{ Performance } & 1 & 0.877 & Valid \\
\hline & 2 & 0.891 & Valid \\
\hline & 3 & 0.897 & Valid \\
\hline & 4 & 0.922 & Valid \\
\hline & 5 & 0.894 & Valid \\
\hline & 6 & 0.808 & Valid \\
\hline & 7 & 0.886 & Valid \\
\hline
\end{tabular}

Sumber: Data diolah oleh peneliti

Sedangkan reliabilitas, menurut Ghozali (2006), adalah alat untuk mengukur kehandalan suatu kuesioner yang merupakan indikator dari variabel atau konstruk. Suatu kuesioner dikatakan reliabel atau handal jika jawaban seseorang terhadap pernyataan adalah konsisten atau stabil dari waktu ke waktu. Uji realibilitas yang digunakan dalam penelitian ini adalah uji Cronbach Aplha. Suatu konstruk atau variabel dinyatakan reliabel jika memberikan nilai Cronbach Alpha > 0.60 (Ghozali, 2006). Hasil Uji Validitas terhadap data penelitian, dengan membandingkan masing-masing nilai Cronbach's Alpha pada setiap variabel atau instrumen penelitian, ditemukan nilai yang lebih besar dari 0,6, sehingga dapat dinyatakan bahwa instrumen penelitian untuk mengukur variabel dalam penelitian ini adalah reliable (Lihat Tabel $3)$.

Tabel 3. Hasil Uji Validitas

\begin{tabular}{ccc}
\hline Variabel & Cronbach's Alpha & Keterangan \\
\hline Personal Knowledge & 0.756 & Reliable \\
Job Procedure & 0.857 & Reliable \\
\hline
\end{tabular}



http://doi.org/10.21009/JRMSI

\begin{tabular}{ccc}
\hline Technology & 0.939 & Reliable \\
Performance & 0.953 & Reliable \\
\hline
\end{tabular}

Sumber: Data diolah oleh peneliti

\section{Uji Asumsi}

Sebelum dilakukan analisis path, terlebih dahulu dilakukan uji asumsi yang mendasari analisis path yaitu uji linieritas dan uji normalitas.

Uji lineritas bertujuan untuk menguji apakah bentuk hubungan antara variabel bebas dan variabel terikat adalah linier atau tidak. Model path yang baik adalah model dimana hubungan antara kedua variabel tersebut adalah linier. Metode yang digunakan dalam menguji linieritas adalah dengan Table ANOVA. Dengan Tabel ANOVA, akan dilihat nilai Sig. Linearity dari setiap variabel bebas dengan variabel terikat dibandingan dengan tingkat signifikansi $(\alpha)$. Nilai Sig. Linearity menunjukkan sejauh mana variabel bebas berbanding tepat di garis lurus. Apabila nilai Sig. Linearity lebih kecil dari tingkat signifikansi $(\alpha)$, maka regresi linier dapat dipergunakan untuk menjelaskan pengaruh antara variabel-variabel yang ada (Prihadi Utomo, 2007). Hasil Uji Linieritas menunjukkan bahwa nilai Sig. Linearity pada seluruh jalur hubungan variabel adalah lebih kecil dari $\alpha=0.05$, sehingga dapat disimpulkan bahwa asumsi linieritas terpenuhi.

Sedangkan Uji normalitas bertujuan untuk menguji apakah residual dalam model path mengikuti sebaran normal atau tidak. Model path yang baik adalah model dimana residualnya mengikuti distribusi normal. Metode yang digunakan dalam menguji normalitas adalah dengan model Histogram dan Normal P-P Plot. Residual model dikatakan mengikuti distribusi normal apabila sebaran data (histogram) mengikuti pola kurva normal atau ketika plot data (sebaran data) mengikuti garis linear P-P Plot. Hasil pengujian disajikan pada Grafik 1.
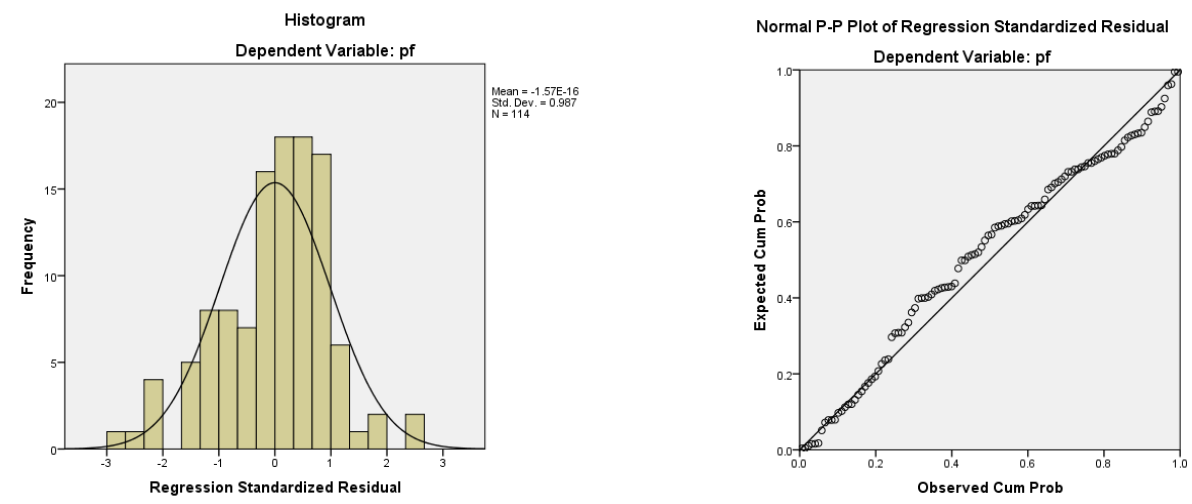


\section{Grafik 1. Hasil Pengujian Normalitas}

Hasil pengujian normalitas pada gambar di atas menunjukkan bahwa histogram sebagian besar tampak mengikuti kurva normal dan scatter plot berada di sekitar garis linier, sehingga dapat dikatakan bahwa sebaran data tersebut berdistribusi normal.

\section{Hasil Analisis}

Setelah melakukan transformasi data dari skala ordinal ke interval dengan Methods of Successive Intervals (MSI), data kemudian dianalisis dengan teknik path analysis sesuai model struktural yang telah dirumuskan sebelumnya. Hasil path analysis ditunjukkan pada Tabel 5 dan 6.

Tabel 4. Hasil Path Analysis Model Struktural 1

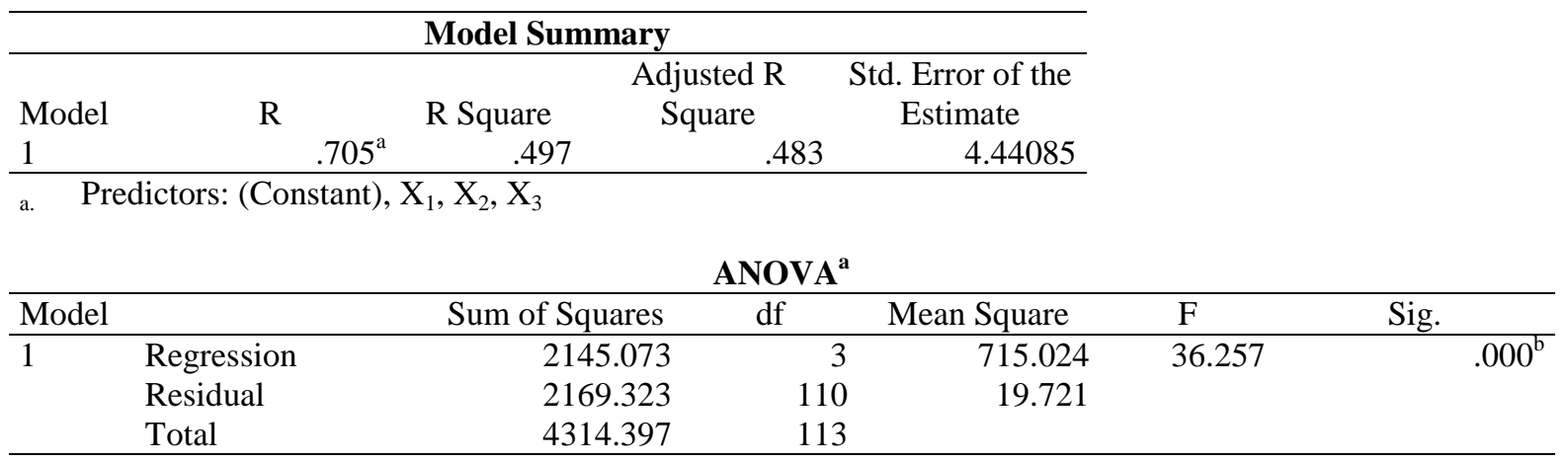

a. Dependent Variable: Y

b. Predictors: (Constant), $\mathrm{X}_{1}, \mathrm{X}_{2}, \mathrm{X}_{3}$

\begin{tabular}{|c|c|c|c|c|c|c|}
\hline \multicolumn{7}{|c|}{ Coefficients $^{\mathrm{a}}$} \\
\hline \multirow{2}{*}{\multicolumn{2}{|c|}{ Model }} & Unstandardize & Coefficients & $\begin{array}{l}\text { Standardized } \\
\text { Coefficients }\end{array}$ & & \\
\hline & & B & Std. Error & Beta & $\mathrm{t}$ & Sig. \\
\hline \multirow[t]{4}{*}{1} & (Constant) & -1.059 & 2.953 & & -.359 & .721 \\
\hline & $\mathrm{X}_{1}$ & .162 & .116 & .116 & 1.391 & .167 \\
\hline & $\mathrm{X}_{2}$ & .414 & .114 & .308 & 3.632 & .000 \\
\hline & $X_{3}$ & .483 & .095 & .417 & 5.101 & .000 \\
\hline
\end{tabular}

a. Dependent Variable: Y

Sumber: Data diolah oleh peneliti

Dari Tabel 4 di atas, persamaan yang terbentuk untuk Model Struktural 1:

$$
\mathrm{Y}=0.116 \mathrm{X}_{1}+0.308 \mathrm{X}_{2}+0.417 \mathrm{X}_{3}+\varepsilon_{1}
$$

Nilai signifikansi pengaruh pada jalur $\mathrm{X}_{1} \rightarrow \mathrm{Y}$ sebesar 0.167 yang lebih besar dari 0.05 , sehingga koefisien pada jalur ini tidak signifian. Nilai signifikansi pengaruh pada jalur $\mathrm{X}_{2} \rightarrow \mathrm{Y}$ dan $\mathrm{X}_{3} \rightarrow \mathrm{Y}$ masing-masing sebesar 0.000 yang lebih kecil dari 0.05, sehingga koefisien pada jalur ini signifikan. Sementara nilai error pada persamaan struktural tersebur diperoleh: ${ }_{\rho} \mathrm{Ye}=\sqrt{1-R^{2}}=\sqrt{1-0.497}=0.709$. 
Hasil uji $\mathrm{F}$ berdasarkan output ANOVA pada Tabel 5 menunjukkan bahwa pengaruh variabel $X_{1}, X_{2}$, dan $X_{3}$ secara bersama-sama berpengaruh terhadap variabel $Y$. Nilai $F$ test sebesar 36.257 dan nilai Sig. sebesar 0.00 yang menunjukkan bahwa pengaruh signifikan dan adanya pengaruh positif (dengan alpha 0,05). Maka dapat ditarik kesimpulan bahwa variabel personal knowledge, job procedure dan technology secara simultan berpengaruh terhadap performance (kinerja pegawai). Dari hasil pengujian di atas, dapat diketahui bahwa adjusted $R$ square sebesar 0,497 atau menunjukkan bahwa sebesar $49.7 \%$ performance (kinerja pegawai) dapat dipengaruhi oleh variabel personal knowledge, job procedure dan technology. Pengaruh dari variabel lain yang tidak termasuk dalam persamaan regresi pada penelitian ini sebesar $50.3 \%$.

Tabel 5. Hasil Path Analysis Model Struktural 2

\begin{tabular}{|c|c|c|c|c|}
\hline \multicolumn{5}{|c|}{ Model Summary } \\
\hline Model & $\mathrm{R}$ & R Square & $\begin{array}{l}\text { Adjusted R } \\
\text { Square }\end{array}$ & $\begin{array}{l}\text { Std. Error of the } \\
\text { Estimate }\end{array}$ \\
\hline 1 & $.532^{\mathrm{a}}$ & .283 & .277 & 3.91262 \\
\hline
\end{tabular}

\begin{tabular}{llrrrrr}
\multicolumn{7}{c}{ ANOVA $^{\mathbf{a}}$} \\
\hline Model & & Sum of Squares & df & Mean Square & F & Sig. \\
\hline 1 & Regression & 676.589 & 1 & 676.589 & 44.197 & $.000^{\mathrm{b}}$ \\
& Residual & 1714.559 & 112 & 15.309 & & \\
& Total & 2391.148 & 113 & & & \\
\hline
\end{tabular}

a. Dependent Variable: $\mathrm{X}_{2}$

b. Predictors: (Constant), $\mathrm{X}_{1}$

\section{Coefficients $^{\mathrm{a}}$}

\begin{tabular}{|c|c|c|c|c|c|c|}
\hline \multirow[b]{2}{*}{ Model } & & \multicolumn{5}{|c|}{$\begin{array}{l}\text { Standardized } \\
\text { Coefficients }\end{array}$} \\
\hline & & B & Std. Error & Beta & $\mathrm{t}$ & Sig. \\
\hline 1 & (Constant) & 6.428 & 2.530 & & 2.541 & .012 \\
\hline & $\mathrm{X}_{1}$ & .553 & .083 & .532 & 6.648 & .000 \\
\hline
\end{tabular}

a. Dependent Variable: $\mathrm{X}_{2}$

Sumber: Data diolah oleh peneliti

Dari Tabel 3 di atas, persamaan yang terbentuk untuk Model Struktural 2:

$\mathrm{X}_{2}=0.532 \mathrm{X}_{1}+\varepsilon_{2}$

Nilai signifikansi pengaruh pada jalur $\mathrm{X}_{1} \rightarrow \mathrm{X}_{2}$ sebesar 0.000 yang lebih kecil dari 0.05 , sehingga koefisien pada jalur ini signifikan. Sementara nilai error pada persamaan struktural tersebur diperoleh $:{ }_{\rho} \mathrm{X}_{2} \mathrm{e}=\sqrt{1-R^{2}}=\sqrt{1-0.283}=0.846$. 
Berdasarkan hasil analisis jalur pada Tabel 5 dan 6 di atas, diperoleh diagram jalur secara lengkap sebagai berikut :

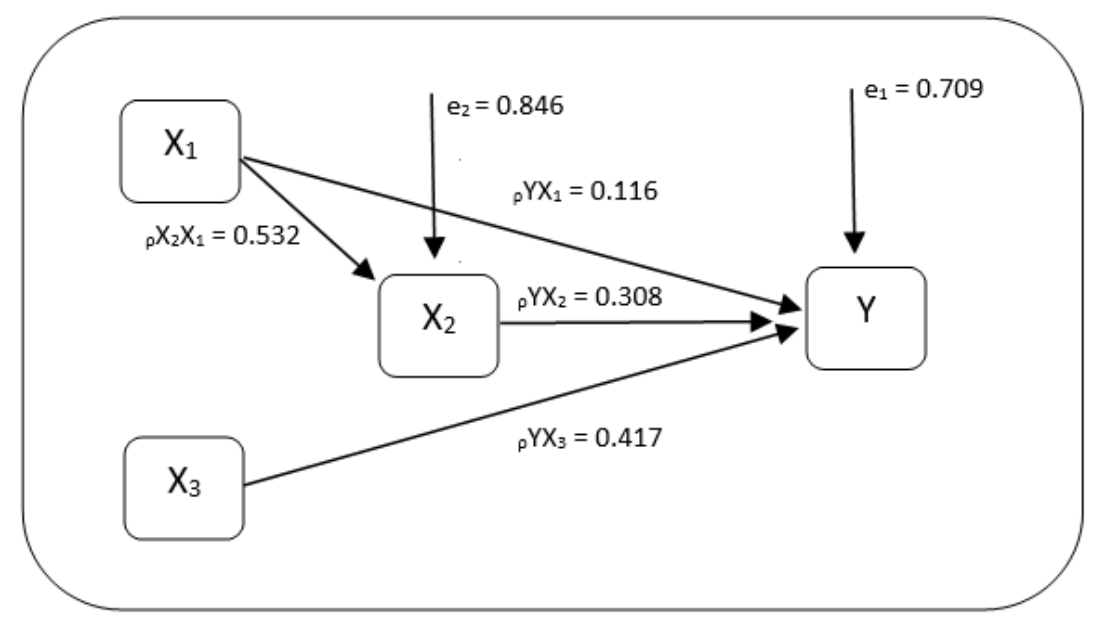

\section{Gambar 2. Diagram Jalur Lengkap}

Dari Gambar 2 di atas, diketahui bahwa pengaruh langsung $\mathrm{X}_{1}$ ke $\mathrm{Y}$ sebesar 0.116, pengaruh langsung $\mathrm{X}_{2}$ ke $\mathrm{Y}$ sebesar 0.308, dan pengaruh langsung $\mathrm{X}_{3}$ ke $\mathrm{Y}$ sebesar 0.417. Adapun pengaruh tidak langsung dan total pengaruh khusus pada jalur hubungan $\mathrm{X}_{1}$ ke $\mathrm{Y}$ melalui $\mathrm{X}_{2}$, diperoleh:

Pengaruh tidak langsung (melalui $\left.\mathrm{X}_{2}\right)=0.532 \times 0.308=0.163$

Total pengaruh $=0.116+0.163=0.279$

\section{Pengaruh Personal Knowledge Terhadap Performance (Kinerja Pegawai)}

Pengaruh personal knowledge terhadap performance (kinerja pegawai) memiliki nilai koefisien jalur 0.116 dan nilai Sig. sebesar 0,167 yang lebih besar dari nilai alpha $(0,05)$. Hal ini berarti bahwa personal knowledge secara statistik tidak memiliki pengaruh yang signifikan terhadap performance (kinerja pegawai). Dengan demikian maka hipotesis pertama $\left(\mathrm{H}_{1}\right)$ penelitian yang menyatakan bahwa ada pengaruh yang signifikan antara personal knowledge terhadap performance (kinerja pegawai) ditolak.Hasil ini sejalan dengan hasil penelitian sebelumnya oleh Kosasih dan Budiani (2007).

Hasil pengumpulan data melalui kuesioner pada bagian pertanyaan terbuka, menguatkan hasil temuan analisis ini, dimana beberapa sampel menyatakan bahwa pengetahuan dan wawasan para pegawai terhadap isu ini belum merata di antara para pegawai, mengingat isu knowledge management di lingkungan BPPK masih relatif baru dan masih dalam tahap pengembangan dan penyempurnaan. Beberapa sampel 
menyatakan bahwa mereka relatif tidak banyak terlibat dalam proses "sharing best practices" dan "sharing knowledge" dalam kerangka knowledge management. Padahal sesungguhnya para pegawai diharapkan dapat bertindak sebagai knowledge worker yang dalam pekerjaannya mereka dapat mengakses, mengolah, menganalisis, menyimpan, dan mentransfer data dan informasi. Fakta-fakta ini diyakini menjadi faktor utama penyebab tidak signifikannya pengaruh personal knowledge pegawai terhadap kinerja mereka. Padahal, peran knowledge worker dalam implementasi knowledge management perlu diselaraskan dan dimanfaatkan secara optimal bagi kepentingan organisasi. Para pimpinan perusahaan harus memahami mereka agar dapat mengelola dan memanfaatkan kemampuan mereka untuk mendukung daya saing organisasi (Lumbantobing, 2016). Di antara langkah yang dapat ditempuh untuk mengefektifkan peran dari knowledge worker menurut Dunamis dalam Lumbantobing (2016) adalah bekerja sama dengan mereka dan memastikan adanya target-target yang harus dicapai. Target-target tersebut sebaiknya dibicarakan dengan mereka dengan tuntunan KPI (Key Performance Indicators).

\section{Pengaruh Job Procedure Terhadap Performance (Kinerja Pegawai)}

Pengaruh job procedure terhadap performance (kinerja pegawai) memiliki nilai koefisien jalur 0.308 dan nilai Sig.sebesar 0,000 yang lebih kecil daripada nilai alpha $(0,05)$. Hal ini menunjukkan bahwa job procedure memiliki pengaruh yang signifikan terhadap performance (kinerja pegawai). Dengan demikian maka hipotesis keempat $\left(\mathrm{H}_{4}\right)$ penelitian yang menyatakan bahwa ada pengaruh yang signifikan antara job procedureterhadap performance (kinerja pegawai) diterima. Hasil ini menunjukkan bahwa keberadaan SOP di lingkungan BPPK yang disusun dengan tujuan agar pekerjaan menjadi terarah dan terkoordinasiserta menjadi sarana komunikasi dalam mencapai sasaran dan tujuan organisasi terbukti mampu memberikan kontribusi yang nyata (signifikan) terhadap pencapaian kinerja pegawai. Dari hasil analisis statistik deskriptif, indikator job procedure berupa tanggung jawab kerja yang jelas dan pekerjaan menjadi terarah dan terkoordinir dengan kleberadaan SOP, memiliki nilai mean tertinggi (4,40 dan 4,39). Hal ini berarti bahwa keberadaan SOP di lingkungan BPPK saat ini diyakini mampu menunjang tercapai kinerja pegwai yang tinggi.

\section{Pengaruh Technology Terhadap Performance (Kinerja Pegawai)}


Pengaruh technology terhadap performance (kinerja pegawai) memiliki nilai koefisien jalur 0.417. Sementara itu, nilai Sig.-nyaadalah 0,000, lebih kecil daripada nilai alpha $(0,05)$. Kedua angka ini menunjukkan bahwa technology memiliki pengaruh yang signifikan terhadap performance (kinerja pegawai). Dengan demikian maka hipotesis kelima $\left(\mathrm{H}_{5}\right)$ yang menyatakan bahwa ada pengaruh yang signifikan antara technology terhadap performance (kinerja pegawai) diterima. Hasil analisis menunjukkan bahwa semakin tinggi tingkat penggunaan technology, berupa media penyebaran informasi melalui sarana intranet yang digunakan untuk mendukung setiap kegiatan kerja di lingkungan internal BPPK, maka akan berpengaruh pada semakin tingginya tingkat capaian kinerja pegawai. Penggunaan technology melalui media intranet BPPK yang meningkatkan produktivitas, kualitas output, dan efektivitas kerja pegawai serta menjadi sarana yang sesuai untuk mendapatkan dan menyebarkan informasi, secara empiris telah mampu menunjang pencapaian kinerja pegawai yang tinggi. Hasil ini juga mendukung hasil penelitian Chong, et al. (2011) dan Choirina (2014). Dari hasil analisis statistik deskriptif, indikator technology berupa fitur-fitur intranet (COMET) yang memberikan manfaat dan menjadi sarana yang sesuai untuk mendapatkan dan menyebarkan informasi memiliki nilai mean tertinggi $(0,384$ dan 0,392). Hal ini berarti bahwa keberadaan intranet (COMET) BPPK saat ini dirasakan sebagai faktor dominan yang dapat meningkatkan kinerja pegawai melalui pemanfaatan berbagai fiturnya untuk kelancaran dan efektivitas pekerjaan. Meskipun demikian, hasil pengumpulan data melalui kuesioner pada bagian pertanyaan terbuka, beberapa sampel menyatakan bahwa akses intranet masih kerap mengalami gangguan sehingga penggunaannya tidak berjalan optimal. Selain itu, sebagian responden juga mengeluhkan sebagian fitur-fitur knowledge management yang kurang menarik dan variatif, sehigga diusulkan agar membuat metode-metode knowledge sharing yang lebih menarik dan menyenangkan. Padahal intranet sebagai knowledge management tool diharapkan sangat membantu dalam memfasilitasi knowledge sharing sehingga knowledge dapat disebarkan secara luas ke semua pegawai yang memiliki akses ke knowledge sharing tool.

\section{Pengaruh Personal Knowledge dalam Terhadap Pemahaman Job Procedure Organisasi}


Pengaruh personal knowledge terhadap job procedure memiliki nilai koefisien jalur 0.532 dan nilai Sig. 0,000 yang lebih kecil dari nilai alpha $(0,05)$. Nilai Sig. yang lebih kecil daripada alpha memiliki arti bahwa personal knowledge memiliki pengaruh yang signifikan terhadap job procedure. Dengan demikian maka hipotesis kedua $\left(\mathrm{H}_{2}\right)$ penelitian yang menyatakan bahwa ada pengaruh yang signifikan antara personal knowledge terhadap job procedure diterima. Hasil ini menunjukkan bahwa semakin tinggi tingkat pengetahuan yang diperoleh pegawai berupa pengalaman atau masa kerja, semakin tinggi pula tingkat pemahaman pegawai akan job procedure organisasi. Begitu pula sebaliknya, pengalaman atau masa kerja yang minim cenderung menjadi penghambat bagi para pegawai dalam memahami job procedure organisasi. Personal knowledge pegawai bukan hanya diperoleh dari diri sendiri tetapi juga dari orang lain, pengalaman baru yang diperoleh setiap hari, mengomunikasikan pengalaman kerja dengan rekan kerja, ikut ambil bagian dalam forum "sharing best practices" atau "sharing knowledge" dan membagikan pengalaman untuk kemajuan organisasi, secara empiris telah mampu menunjang pemahaman pegawai akan job procedure organisasi yang lebih baik. Hasil ini juga mendukung penelitian oleh Kosasih dan Budiani (2007).

\section{Pengaruh Tidak Langsung Personal Knowledge Terhadap Performance (Kinerja}

\section{Pegawai) yang Dimediasi oleh Variabel Job Procedure}

Pengaruh tidak langsung personal knowledge terhadap performance yang dimediasi oleh variabel job procedure memiliki nilai koefisien jalur 0.163 . Sementara itu, nilai Sig.-nya adalah 0,000, lebih kecil dari nilai alpha $(0,05)$. Hal ini berarti bahwa personal knowledge memiliki pengaruh yang signifikan terhadap performance yang dimediasi oleh job procedure. Dengan demikian maka hipotesis ketiga $\left(\mathrm{H}_{3}\right)$ yang menyatakan bahwa ada pengaruh yang signifikan antara personal knowledge terhadap perfomance yang dimediasi oleh job procedure diterima.Hasilini menunjukkan bahwa pengaruh langsung personal knowledge terhadap performance menunjukkan arah yang positif dengan nilainya yangkecil yaitu sebesar 0,162. Namun apabila melihat pengaruh secara total antara personal knowledge dan job procedure terhadap performance maka perolehan nilainya akan lebih besar yaitu 0,228. Artinya, personal knowledge yang diimbangi (mediasi) dengan pemahaman terhadap job procedure akan memberikan pengaruh yang baik bagi kinerja pegawai. Hasil penelitian sejalan dengan Kosasih dan Budiani (2007). 

http://doi.org/10.21009/JRMSI

\section{KESIMPULAN DAN SARAN}

Berdasarkan tujuan, hasil analisis, dan pembahasan penelitian ini, diperoleh kesimpulan sebagai berikut: (1) personal knowledge tidak terbukti secara signifikan memengaruhi performance (kinerja pegawai), job procedure terbukti secara signifikan memengaruhiperformance (kinerja pegawai), dan technology terbukti secara signifikan memengaruhiperformance (kinerja pegawai); (2) personal knowledge terbukti secara signifikan memengaruhi pemahaman pegawai akan job procedure organisasi; dan (3) personal knowledge terbukti secara signifikan memengaruhi performance (kinerja pegawai) yang dimediasi oleh job procedure.

Dari hasil penelitian ini, terdapat beberapa rekomendasi yang dapat diberikan, yaitu: (1) Mengingat tidak signifikannya pengaruh personal knowledge terhadap kinerja dan rendahnya kepedulian dan keterlibatan pegawai dalam implementasi knowledge management maka disarankan agar peran pegawai dalam implementasi knowledge management sebagai knowledge source dapat dikuatkan dengan mengaturnya dalam Indikator Kinerja Utama (IKU) pegawai. Tujuan dari langkah ini adalah agar para pegawai sebagai knowledge worker didorong untuk melakukan knowledge sharing dan para pimpinan harus memastikan bahwa upaya mereka dalam melakukan knowledge sharing diakui dan dihargai oleh organisasi. Hal ini penting karena para pegawai dalam jangka panjang adalah sumber knowledge yang sangat potensial. Adalah tidak realistis menuntut pegawai atau anggota organisasi untuk melakukan knowledge sharing tanpa mempertimbangkan apa yang akan diperoleh atau kerugian apa yang mungkin dialami oleh mereka yang membagikan pengetahuannya; (2) Dominannya pengaruh technology terhadap performance (kinerja pegawai) dibandingkan indikator personal knowledge dan job procedure dalam kerangka knowledge management yang dilihat dari nilai koefisien jalur yang paling besar, menunjukkan pentingnya peran teknologi khususnya intranet (COMET) BPPK dalam kesuksekan implementasi knowledge management. Oleh karena itu, dukungan terhadap pengembangan dan penyempurnaan media ini harus terus dikuatkan, di antaranyadenganpengalokasian anggaran yang memadai dan pemberian penghargaan (reward) kepada para pegawai yang bertindak sebagai perancang, pembangun, dan pengelola sistem tersebut. Meski demikian, diharapkan agar pimpinan dan penentu kebijakan dalam implementasi konsep tidak mengurangi perhatiannya terhadap peran para pegawai karena sesungguhnya implementasi 
knowledge managementberpusat kepada manusia, dimana sebagian besar knowledge berada di dalam kepala manusia dalam bentuk tacit knowledge, bukan terletak di dalam sistem informasi yang canggih. Kenyataan ini membawa kita kepada kesadaran bahwa pendekatan-pendekatan yang bersifat people centered tidak hanya sekedar perlu, tetapi sudah menjadi keharusan untuk dilakukan.Salah satu cara pendekatan yang berpusat kepada manusia adalah dengan menumbuhkan budaya yang kondusif terhadap berjalannya proses-proses di dalam knowledge management, mulai dari proses knowledge creation, knowledge retention, knowledge transfer/sharing dan knowledge utilization.

Penelitian berikutnya dalam case ini disarankan dapat difokuskan pada aspek awareness atau kepedulian para pegawai terkait implementasi knowledge management. Hal ini diharapkan agar konsepnya dapat dibangun dengan lebih matang dan sempurna di masa yang akan datang.

\section{DAFTAR PUSTAKA}

Ariola et al. (2006). Principles and Methods of Research. Rex Bookstore Inc., Sampaloc.

Bahm, Archie J. (1995). Epistemology; Theory of Knowledge. Albuquerque.

Bernardin, R. A. (1993). Human Resource Management: An Experimental Approach. Singapore: McGraw Hill.

Carrillo, P., Robinson, H., Al-Ghassani, A., Anumba, C. (2004). Knowledge Management in UK Construction: Strategies, Resources and Barriers. Project Management Journal, 35, (1), p. 46.

Choirina, Frisca Devi. (2014). Analisis Pengaruh Praktek Knowledge Management Dalam Memediasi Dukungan Information Technology Terhadap Kinerja Karyawan (Studi Pada Kantor Perwakilan Bank Indonesia Wilayah V Semarang). Skripsi. Fakultas Ekonomika dan Bisnis Universitas Diponegoro Semarang

Chong, Alain Y.L., Felix T.S. Chan, K.B. Ooi, J.J. Sim. (2011). Can Malaysian firms improve organizational/innovation performance via SCM?. Journal of Industrial Management \& Data Systems, Vol. 111 Issue: 3, pp.410-431

Debowski, Shelda. (2006). Knowledge Management, Melbourne and Sydney: John Wiley and Son Australia, Ltd. 
Ghozali, Imam. (2006). Structural Equation Modelling Metode Alternatif Dengan Partial Least Square, edisi 2. Semarang: BP-UNDIP.

Herusantoso, Khamami, Ilhan Lasahido. (2012). Kajian Penerimaan Teknologi Intranet di Badan Pendidikan Dan Pelatihan Keuangan (BPPK). Kajian Akademis BPPK, Jakarta.

Honeycutt, J. (2005). Knowledge Management Strategies; Strategi Manajemen Pengetahuan. Jakarta: PT. Elex Media Komputindo.

Keputusan Menteri Keuangan Republik Indonesia Nomor 127/KMK.01/2013 Tentang Program Budaya di Lingkungan Kementerian Keuangan.

Kosasih, N. dan Budiani, S. (2007). Pengaruh Knowledge management Terhadap Kinerja Karyawan: Studi Kasus Departemen Front Office Surabaya Plaza Hotel. Jurnal Manajemen Perhotelan, 3(2) September: 80-88.

Kusnendi. (2008). Model-Model Persamaan Struktural: Satu dan Multigroup Sampel dengan LISREL. Bandung: CV. Alfabeta.

Laudon, Kenneth C. dan Laudon, Jane P. (2008). Sistem Informasi Manajemen. Terjemahan Chriswan Sungkono dan Machmudin Eka P. Edisi 10. Jakarta: Salemba Empat.

Lumbantobing, Paul. (2016). Knowledge Management: Konsep, Arsitektur dan Implementasi - Edisi Kedua. Bandung: KMSI.

Nawawi, Ismail. (2012). Manajemen Pengetahuan (Knowledge Management) Teori dan Aplikasi Dalam Mewujudkan Daya Saing. Bogor: Penerbit Ghalia Indonesia.

Nazir, M. (2003). Metodologi Penelitian. Jakarta: Ghalia Indonesia.

Polanyi, Michael. (1966). The Tacit Dimension. Garden City, New York: Doubleday Company Inc. ISBN: 978-0-226-67298-4.

Prihadi Utomo, Yuni. (2007). Eksplorasi Data dan Analisis Regresi dengan SPSS. Surakarta: Muhammadiyah University Pess.

Ra'ed Masa'deh, Rifat Shannak, Mahmoud Maqableh, Ali Tarhini. (2017). The Impact of Knowledge Management on Job Performance in Higher Education: The Case of The University of Jordan. Journal of Enterprise Information Management, Vol. 30 Issue: 2 , pp.244-262.

Sekaran, Uma. (2006). Research Methods For Business: Metodologi PenelitianUntuk Bisnis, Buku 2. Jakarta: Salemba Empat 
Somad, Rismi. (2013). Pengaruh Budaya Organisasi dan Komitmen Organisasional Terhadap Kualitas Pelayanan Pegawai Hotel Berbintang Empat di Kota Bandung (Survei Terhadap Pegawai Customer Services). Jurnal Bisnis dan Manajemen, Vol. 9 No. 3, Mei 2013, (320-422)

Sulastiyono, A. (2001). Manajemen Penyelenggara Hotel. Bandung: Alfabeta.

Takeuci, Hirotaka. (1998). Beyond Knowledge Management: Lessons from Japan. WWW Virtual Library on Knowledge Management, June, hal.6 dan lihat juga Sveiby, Karl Erik. (1996). The New Organizational Wealth: Managing and Measuring Knowledge-Based Assets, San Fransisco: Berret-Koehler Publishers, Inc, hal.46-49.

Tiwana A. (2000). The Knowledge Management Toolkit. Prentice Hall PTR Upper Saddle River, NJ 07458 McGraw Hill. 